\title{
JUURNAL.RU
}

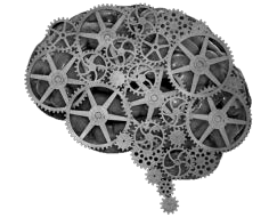

COMPANY GROUP "INTELLEKT"

\author{
Бобров Н.И., Бородина Г.Н., Черников Ю.Ф. \\ Алтайский Государственный Медииинский Университет \\ Барнаул, Россия
}

doi: 10.18411/lj2016-3-63

\section{Вариантные и возрастные особенности анатомии дельтовидной мышцы}

Актуальность своевременной и правильной диагностики травмы скелетномышечной системы обусловлена её широкой распространённостью и огромными материальными потерями общества, сопряжёнными с нею. Диагностика повреждений плечевого сустава, в силу анатомических особенностей и биомеханики сустава, представляет особую трудность. Поэтому одной из важных задач является изучение анатомических и вариантных особенностей строения плечевого устава.

При повреждении мягкотканых компонентов плечевого сустава наиболее часто встречается повреждение вращательной манжеты, которое в 90-95\% случаев приводит к нарушению функции. Наиболее часто это повреждение напрямую связано с профессиональной деятельностью людей, занятых тяжёлым физическим трудом [1].

Вращательная манжета представлена капсулой сустава и четырьмя мышцами: надостной, подостной, подлопаточной и большой грудной, сухожилия которых прикрывает дельтовидная мышца. В некоторых случаях пространство между головкой плечевой кости и акромионом достаточно узкое, что приводит к постоянной травматизации сухожилий ротаторной манжеты (особенно часто - сухожилия надостной мышцы). К этому может привести перелом большого бугорка плечевой кости, который сросся со смещением или 
индивидуальная анатомическая форма акромиального отростка плечевой кости: у некоторых людей кончик акромиона имеет форму крючка, который трётся о сухожилие [3].

Цель исследования - изучить размеры и форму контура дельтовидной мышцы методом антропометрических измерений.

Материал и методы: В исследовании принимали участие пациенты травматологического отделения Алейской ЦРБ Алтайского края в возрасте от 1 до 83 лет. Все испытуемые были разделены на 3 группы (табл. №1). Производили измерения сантиметровой лентой по контуру дельтовидной мышцы (рис. 1). Статистическая обработка результатов исследования была проведена с использованием программ «Excel» из пакета Microsoft Office 2003 и «Statistica» 6.0 [2]. Рассчитывали среднеарифметическое значение всех исследуемых параметров. Коэффициент выпуклости $(\mathrm{K})$ определяли по формуле: (ширину умножали на 100 и делили на длину).

Таблица №1

Распределение пациентов на группь

\begin{tabular}{|c|c|c|c|c|}
\hline & \multirow{2}{*}{ Мужчины } & \multirow{2}{*}{ Женщины } & \multicolumn{2}{|c|}{ Дети } \\
\cline { 4 - 5 } & & & мальчики & девочки \\
\hline Количество & 25 & 21 & 3 & 3 \\
\hline Средний возраст & 39 & 52 & 8 & 7 \\
\hline
\end{tabular}

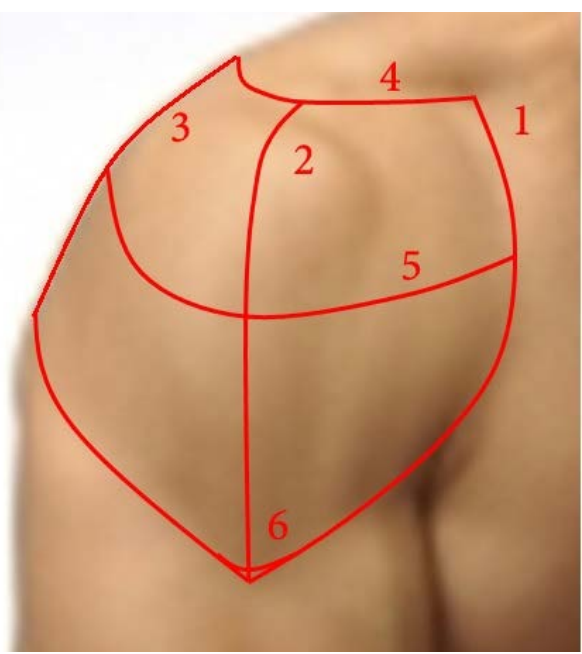

Рис. 1 Исследуемая область проекции дельтовидной мышцы: 1- длина по переднему краю; 2 длина по середине мышцы; 3 - длина по заднему краю; 4 - ширина по верхней линии; 5 ширина по средней линии; 6 - ширина по сухожилию мышщы. 
Результаты и их обсуждения. В результате проведенного исследования установлено, что средний возраст исследуемых мужчин составил 39 лет, рост 174 см, вес 79 кг. Длина дельтовидной мышцы по переднему краю, средней

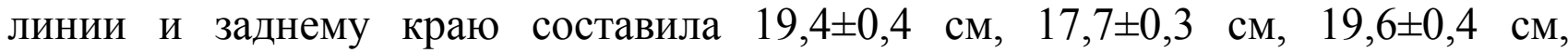
соответственно. Ширина по верхнему краю, средней линии и сухожилию

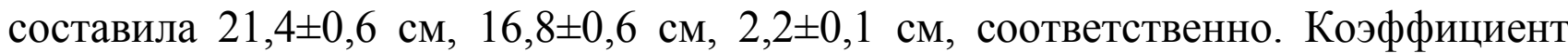
выпуклости равен 96\% (табл. №2).

Таблица №2

Параметры дельтовидной мышиы у мужчин

\begin{tabular}{|c|c|c|c|c|c|c|}
\hline \multicolumn{3}{|c|}{ Длина дельтовидной мышцы, см } & \multicolumn{3}{|c|}{$\begin{array}{c}\text { Ширина дельтовидной мышцы, } \\
\text { см }\end{array}$} & $\begin{array}{l}\text { Коэффициент } \\
\text { выпуклости, \% }\end{array}$ \\
\hline $\begin{array}{c}\text { Передний } \\
\text { край }\end{array}$ & & & $\begin{array}{c}\text { Верхний } \\
\text { край }\end{array}$ & & $\begin{array}{c}\text { Сухожили } \\
\text { e }\end{array}$ & 96 \\
\hline $19,4 \pm 0,4$ & $17,7 \pm 0,3$ & $19,6 \pm 0,4$ & $21,4 \pm 0,6$ & $16,8 \pm 0,6$ & $2,2 \pm 0,1$ & \\
\hline
\end{tabular}

Средний возраст исследуемых женщин составил 52 года, рост $163 \mathrm{~cm}$, вес 73 кг. Все исследуемые параметры у лиц женского пола немного меньше, чем у мужчин. Так, длина дельтовидной мышцы по переднему краю, средней линии и

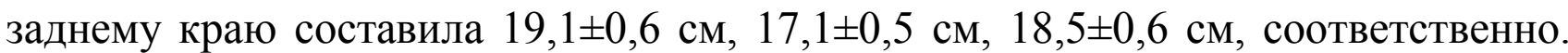
Ширина по верхнему краю, средней линии и сухожилию составила $18,7 \pm 0,5$ см, $15 \pm 0,4$ см, 2 $\pm 0,1$ см, соответственно. Коэффициент выпуклости равен 89\% (табл. №3).

Таблица №3

Параметры дельтовидной мышщы у женщин

\begin{tabular}{|c|c|c|c|c|c|c|}
\hline \multicolumn{3}{|c|}{ Длина дельтовидной мышцы, см } & \multicolumn{3}{|c|}{ Ширина дельтовидной мышцы, см } & $\begin{array}{c}\text { Коэффицие } \\
\text { нт }\end{array}$ \\
\hline $\begin{array}{c}\text { Передний } \\
\text { край }\end{array}$ & $\begin{array}{c}\text { Середины } \\
\text { мышцы } \\
\end{array}$ & $\begin{array}{c}\text { Задний } \\
\text { край }\end{array}$ & $\begin{array}{l}\text { Верхний } \\
\text { край }\end{array}$ & $\begin{array}{c}\text { Середина } \\
\text { мышцы }\end{array}$ & $\begin{array}{c}\text { Сухожили } \\
\text { e }\end{array}$ & \multirow{2}{*}{89} \\
\hline $19,1 \pm 0,6$ & $17,1 \pm 0,5$ & $\begin{array}{c}18,5 \pm 0 \\
6\end{array}$ & $18,7 \pm 0,5$ & $15 \pm 0,4$ & $2 \pm 0,1$ & \\
\hline
\end{tabular}


Средний возраст исследуемых мальчиков составил 8 лет, рост 118 см, вес 26 кг. Длина дельтовидной мышцы по переднему краю, средней линии и заднему краю составила $13,7 \pm 1,8 \mathrm{~cm}, 11,3 \pm 0,6 \mathrm{~cm}, 13 \pm 1 \mathrm{~cm}$, соответственно. Ширина по верхнему краю, средней линии и сухожилию составила $12,6 \pm 1,3$ см, $9,6 \pm 0,4$ см, 1,2 $\pm 0,2$ см, соответственно. Коэффициент выпуклости равен $86 \%$ (табл. №4).

Таблица №4

Параметры дельтовидной мышщьы у мальчиков

\begin{tabular}{|c|c|c|c|c|c|c|}
\hline \multicolumn{3}{|c|}{ Длина дельтовидной мышцы, см } & \multicolumn{3}{|c|}{$\begin{array}{c}\text { Ширина дельтовидной мышцы, } \\
\text { см }\end{array}$} & $\begin{array}{c}\text { Коэффицие } \\
\text { нт } \\
\text { выпуклости, }\end{array}$ \\
\hline$\underset{\text { Прай }}{\text { Переднй }}$ & $\begin{array}{l}\text { Середины } \\
\text { мышшы }\end{array}$ & $\begin{array}{c}\text { Задний } \\
\text { край }\end{array}$ & $\begin{array}{c}\text { Верхний } \\
\text { край }\end{array}$ & $\begin{array}{c}\text { Середин } \\
\text { а мышшы }\end{array}$ & $\begin{array}{c}\text { Сухожили } \\
\text { e }\end{array}$ & 86 \\
\hline $13,7 \pm 1,8$ & $11,3 \pm 0,6$ & $13 \pm 1$ & $12,6 \pm 1,3$ & $9,6 \pm 0,4$ & $1,2 \pm 0,2$ & \\
\hline
\end{tabular}

Средний возраст исследуемых девочек составил 7 лет, рост 120см, вес 27 кг. Длина дельтовидной мышцы по переднему краю, средней линии и заднему

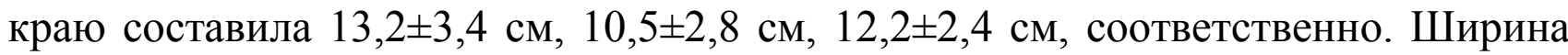
по верхнему краю, средней линии и сухожилию составила 12,3 $\pm 2,6 \mathrm{~cm}, 8 \pm 2,1 \mathrm{~cm}$,

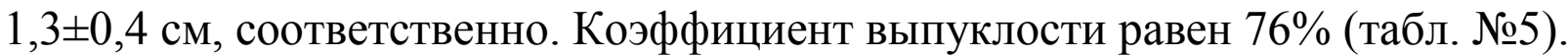

Таблицุа №5

Параметры дельтовидной мышщьь у девочек

\begin{tabular}{|c|c|c|c|c|c|c|}
\hline \multicolumn{3}{|c|}{ Длина дельтовидной мышцы, см } & \multicolumn{3}{|c|}{$\begin{array}{c}\text { Ширина дельтовидной мышцы, } \\
\text { см }\end{array}$} & $\begin{array}{c}\text { Коэффициент } \\
\text { выпуклости, } \\
\%\end{array}$ \\
\hline $\begin{array}{c}\text { Передний } \\
\text { край }\end{array}$ & $\begin{array}{c}\text { Середины } \\
\text { мышцы }\end{array}$ & $\begin{array}{l}\text { Задний } \\
\text { край }\end{array}$ & $\begin{array}{c}\text { Верхний } \\
\text { край }\end{array}$ & $\begin{array}{c}\text { Середина } \\
\text { мышцы }\end{array}$ & Сухожилие & 76 \\
\hline $13,2 \pm 3,4$ & $10,5 \pm 2,8$ & $12,2 \pm 2,4$ & $12,3 \pm 2,6$ & $8 \pm 2,1$ & $1,3 \pm 0,4$ & \\
\hline
\end{tabular}

\section{Выводы.}

1. По всем показателям дельтовидная мышца у мужчин больше, чем у женщин на 6,8\% (ширина на 9,4\%, длина на 4,3\%). 
2. Размеры дельтовидной мышца мальчиков в детском возрасте на $4 \%$ больше, чем у девочек (ширина на $2 \%$, длина на 6\%).

3. Гендерные различия у взрослых больше в ширину, а у детей - в длину.

4. Ширина дельтовидной мышцы в надплечье уменьшается к середине на $21 \%$, а к месту прикрепления сухожилия - на $89,5 \%$.

\section{Литература:}

1. Беличенко О.И. Магнитнорезонансная томография в диагностике цереброваскулярных заболеваний // О.И. Беличенко, С.А. Дадвани, Н.Н. Абрамова, С.К. Тернова. - М.: ВидарМ., 2002.

2. Реброва О.Ю. Статистический анализ медицинских данных. Применение пакета прикладных программ Statistika. - М.: МедиаСфера, 2003. - 312 с.

3. URL: http://travmaorto.ru/115.html (дата обращения: 12.08.2015) 